\title{
A New Framework to Evaluate Sustainable Higher Education: An Analysis of China
}

\author{
Yuqing Geng $\mathbb{D},{ }^{1}$ Hongwei Zhu $\mathbb{D},{ }^{2}$ Nan Zhao, ${ }^{1}$ and Qinghua Zhai ${ }^{3}$ \\ ${ }^{1}$ School of Business, Shanghai Dianji University, Shanghai 201306, China \\ ${ }^{2}$ School of Communication, East China University of Political Science and Law, Shanghai 201620, China \\ ${ }^{3}$ School of Urban and Regional Science, East China Normal University, Shanghai 200241, China \\ Correspondence should be addressed to Hongwei Zhu; zhuhw007@163.com
}

Received 10 January 2020; Revised 10 May 2020; Accepted 12 May 2020; Published 25 June 2020

Academic Editor: J. R. Torregrosa

Copyright (C) 2020 Yuqing Geng et al. This is an open access article distributed under the Creative Commons Attribution License, which permits unrestricted use, distribution, and reproduction in any medium, provided the original work is properly cited.

\begin{abstract}
The 7E framework to evaluate sustainable higher education proposed in this article is a new and comprehensive one and enjoys the simplicity to remember and spread. This article selects regions of China and compares the development status and coupling coordination level of sustainable higher education both temporally and spatially from the aspects of expenditure, existence, efficiency, effectiveness, economy, equity, and equality based on the 7E framework with the combined method of information entropy weight analysis and technique for order preference by similarity to an ideal solution and coupling coordination degree model. Applicable, generalizable, and constructive countermeasures of sustainable higher education for different regions are also proposed according to the analysis results, which are also references to other places with similar conditions in the world. The framework and the methods are proved effective and useful in evaluating sustainable higher education.
\end{abstract}

\section{Introduction}

Higher education has been widely accepted as a useful and significant channel to promote economic and social growth [1]. Certain countries have enjoyed the benefits of higher education in aspects of economy, social welfare, and human resources after starting strategies and programs aiming to enhance the competitiveness of higher education, which also in turn proves the importance of higher education and enhances the continuous focus on higher education [2-5]. The connotation of sustainability was proposed by the United Nations (UN), which links sustainability with higher education; since then the philosophy or the idea of sustainable higher education has gradually become an agreement [6]. The concepts of University Version.1 (focusing on university development), University Version.2 (focusing on research and teaching promotions), and University Version. 3 (focusing on contributions of universities to social growth) were constructed in the past decades $[7,8]$, which roused widespread attention and had been the main principles of evaluating higher education. However, these concepts fail to focus on higher education with the philosophy of sustainability, thus University Version.4 was constructed [9], aiming to emphasize the sustainable development of higher education and the sustainable interactions between university and other related factors.

The UN interprets the meaning of sustainable education, for example, qualified education (including basic, higher, and vocational education) should be provided with affordable and accessible facilities regardless of gender or disabilities; besides, learners can acquire the knowledge to enhance sustainability with the help of qualified teachers [2]. Sustainable higher education in China has developed significantly in both quality and quantity in recent decades. The government in China took a variety of detailed policies to promote the contribution of sustainable higher education to citizens, economy, and society [10]; however, there are still regional and factorial disbalances of sustainable higher education in China, and higher education is still relatively loose in helping sustainable development of universities and 
society [11]; besides, some elements are still restricting the sustainable improvement of higher education in certain regions [12].

In order to further understand sustainable higher education, it is required to explore the elements of sustainable higher education, construct a proper meanwhile comprehensive framework with the idea of sustainability, and evaluate the development status and the relationship of coupling coordination of sustainable higher education. The analysis results will be beneficial to the comprehension of the sustainable higher education status and to the proposition of practical countermeasures for further coordinated development of sustainable higher education in all aspects.

\section{Literature Review}

2.1. Evaluation Framework of Sustainable Higher Education. Endeavors have been made to evaluate sustainable higher education from the perspectives of multinational, national, and local areas, respectively [13-15], and it is proposed that sustainable higher education should consider the balanced development of various related factors such as institutions, financial situations, fairness, equality, and responsibility of higher education [16-21]. Sustainable higher education contributes to and interacts with the surrounding related factors, and there is coupling coordination mechanism among the factors within the sustainable higher education system; therefore, its connotation is quite integrated and complicated. After the connotation and the coordination mechanism of sustainable higher education are clear, it is then possible for us to figure out frameworks to evaluate the development and coordination statuses of sustainable higher education [22].

It is needed to consider the goals of sustainable higher education when figuring out evaluation frameworks. There are several main goals of higher education: research, teaching, and social contributions [23], which are the aspects to evaluate sustainable higher education. From the research perspective, scholars find that scientific research enhances the competitiveness of higher education; meanwhile, it links corporations and accelerates economic interactions [24, 25]. From the teaching perspective, it is believed that competitive sustainable higher education should provide suitable and well-recognized programs or courses with outstanding teachers to students who can contribute to sustainable higher education with the equipped knowledge and skills after their graduation [26-28]. Besides, in order to continuously contribute to sustainable higher education, students need to receive lifelong education, which means that competitive higher education should provide continuous and lifelong higher education opportunities. From the social contribution perspective, sustainable higher education emphasizes its contributions to society, culture, diversity, economy, and product output $[2,29]$.

Considering the interactions of sustainable higher education with surrounding factors, multilateral cooperation and communication, which is also one of the goals of sustainable education, should be considered as the aspect to evaluate sustainable higher education [2]. In detail, reputational comments from the academic communities or the public-identified as communication results-can be considered to evaluate sustainable higher education [30]. Besides, the benefits of human beings from sustainable higher education, such as equal opportunities and inclusive environment to receive higher education and equal chances to participate in sustainable higher education-related activities, are discussed as the evaluation aspects $[2,31,32]$. In addition, competitive sustainable higher education is affected by the dynamic changes of industrial structures, social value, population, etc., thus whether higher education is modified in accordance with the changing trends and is developing efficiently and effectively should be considered and evaluated [33-35]. Furthermore, considering the interactive functions of sustainable higher education, it is also needed to consider the innate resources of sustainable higher education and equipment of higher education institutions [36, 37].

In conclusion, though providing useful references and insights, current studies regarding the frameworks to evaluate sustainable higher education have some deficiencies: (1) the frameworks are usually complex so that it is difficult to remember, communicate, or widely spread; (2) certain factors are overlapped, making the evaluation frameworks less effective; (3) some factors are based on personal preferences (such as reputational comments), making the frameworks less objective and more doubtful; (4) certain factors ignore the connotation of sustainability and do not reflect the interactions between sustainable higher education and the surrounding environment. Therefore, a more comprehensive, easy to recall, applicable, objective, and sustainable framework should be constructed to better evaluate sustainable higher education.

\subsection{Evaluation Methodology of Sustainable Higher Education.} Currently, there are two types of approaches to evaluate sustainable higher education: qualitative and quantitative. Qualitative approaches are mostly used to explain the origin and development of sustainable higher education [38, 39]; quantitative approaches are mostly used to explore sustainable higher education's development capabilities, correlation factors, coupling statuses, etc. [31, 40, 41] It can be found that current studies usually select specific universities as cases; it is needed to consider sustainable higher education as a whole and explore a detailed, cross-regional, and dynamic coordination analysis of sustainable higher education.

Weighting and aggregation are normally the fundamental processes of evaluating sustainable higher education. There are two types of approaches for weighting: objective approaches and subjective approaches. The objective approaches, e.g., information entropy weight analysis (IEW), cluster analysis, grey correlation analysis, principal component analysis, and technique for order preference by similarity to an ideal solution (TOPSIS), are usually utilized to obtain weights via data $[30,42-45]$. Former studies have proved the deficiencies of these methods: cluster analysis and grey correlation analysis are likely to have less satisfactory performances if they are used solely without combining 
other methods; principal component analysis is likely to lose certain related key elements when main components are extracted. The subjective approaches, e.g., the Delphi method and analytic hierarchy process analysis, are used to get the weights through getting values by professionals $[46,47]$. They are relatively easy to exaggerate or decrease the impact of some indicators due to personal bias so that the preciseness and objectivity of evaluation frameworks may be improperly affected.

The combination of IEW-TOPSIS is a more preferred approach to evaluate sustainable higher education [43]. Proposed by Shannon, IEW has been playing an important and useful role in evaluating the uncertain statuses of the system since 1948. Higher value of IEW represents less variations and more balanced status of the system; therefore, it is possible for us to calculate the IEW value in order to obtain the variation degrees of indicators within the system, which, namely, are the indicators' weights [48, 49]. IEW obtains weights of indicators through data calculations, which guarantees objectivity and avoids subjectivity based on personal preferences. Besides, IEW-TOPSIS is an improved method compared with the traditional TOPSIS approach. The rankings of the research alternatives are determined by the ranking technique where the distances between the alternatives and the ideal solutions are calculated. It reflects the relative importance of the alternatives according to the data with time sequences, which makes this approach more objective and applicable to evaluate sustainable higher education [50].

In conclusion, in the field of evaluation methodology, some studies are based on subjective approaches, leading to the result that the evaluations may be biased with personal preferences; meanwhile, some studies select certain objective approaches which also have deficiencies and lead to less persuasiveness. Therefore, this article uses IEW-TOPSIS, which outweighs other approaches and is the improvement over other options because it is based on the data and guarantees the objectivity of the evaluation results.

\section{Research Area}

The sustainable higher education in China is quickly growing these years due to the emphasis on sustainable development and the initiations of programs aiming to enhance sustainable higher education. This study selects the 31 regions of China as cases and makes spatial-temporal analysis of the development and coupling coordination statuses of sustainable higher education. 3 regions of China (Taiwan, Hong Kong, and Macau) are not selected mainly because the statistical standards are not the same. The 31 regions in this study include Chongqing, Inner Mongolia, Hebei, Jiangsu, Jilin, Zhejiang, Xinjiang, Yunnan, Anhui, Tibet, Hubei, Qinghai, Hunan, Shaanxi, Gansu, Heilongjiang, Fujian, Guizhou, Henan, Ningxia, Shanghai, Guangdong, Hainan, Sichuan, Tianjin, Shanxi, Liaoning, Shandong, Beijing, Guangxi, and Jiangxi (Figure 1).

The spatial-temporal analysis of the regions in China is meaningful to understand the sustainable higher education comprehensively. (1) The analysis of the dynamic evolution

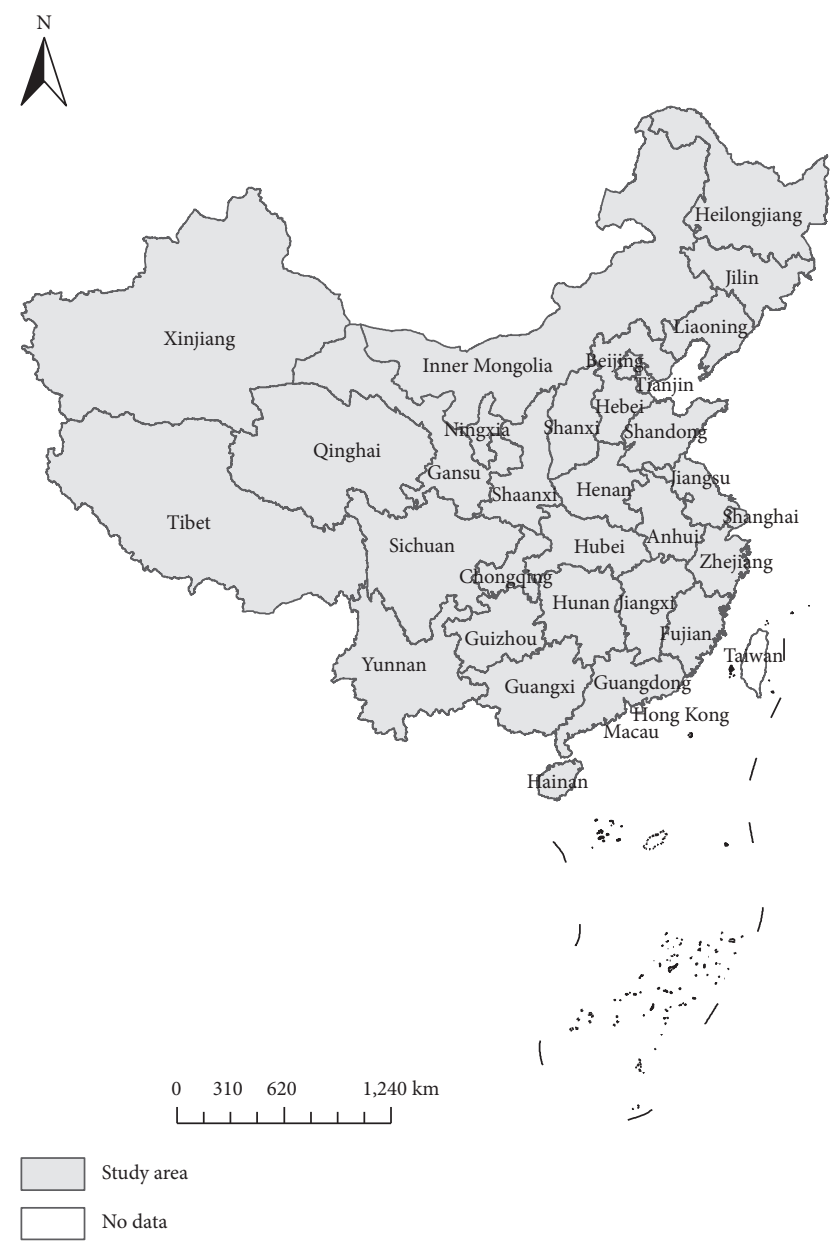

FiguRE 1: Research area.

provides a new and changing opportunity to understand sustainable higher education; (2) regions of China have different, complicated, varied, and special features, and it is possible to find other corresponding places with similar situations or features in the world; therefore, specific countermeasures of developing sustainable higher education for different regions in China are also applicable to those corresponding places; (3) the analysis based on the provincial regions of China acts as a new reference to crossregional higher education research, as former studies mainly select specific universities or places (an individual region or country) as research cases and ignore regional comparisons.

\section{Study Methods}

4.1. Framework Construction. The sustainable higher education evaluation framework in this article is different compared with former frameworks because the one in this article considers the coordination among factors of sustainable higher education and the connotations of sustainability and thus is more complicated, integrated, and comprehensive. In this study, after reviewing former literature, the evaluation framework for sustainable higher education (namely, the 7E framework) is constructed including the aspects of expenditure, existence, efficiency, 
effectiveness, economy, equity, and equality. In detail, expenditure refers to the degree of emphasis on sustainable higher education and reflects the interactions of it with financial investment or expenditures. Existence refers to the factual competitiveness of sustainable higher education from the quantity perspective. Efficiency refers to the competitiveness from the quality perspective and reflects the interactions with development efficiency. Effectiveness refers to the performance of scientific research of sustainable higher education, which reflects the interactions with science and technology. Economy refers to the contribution of sustainable higher education to the local regional economic growth and reflects the interactions with economy development. Equity refers to the fairness of participating relevant sustainable higher education activities from the quantity perspective and reflects the interactions with public involvement. Equality refers to the equal opportunities of participating in sustainable higher education activities for women and international participants from the quality perspective and reflects the interactions with equal chances and inclusive social values. The 7E framework is a new one: it evaluates sustainable higher education from both quality and quantity perspective, combines input and output from the aspects of research, teaching and economic contributions, and emphasizes the fairness of the public; therefore, the 7E framework is more applicable to comprehensively evaluate sustainable higher education. Figure 2 exhibits the structure of the 7E framework.

According to the 7E framework, the selection of indicators for the 7 aspects are proposed, which are illustrated below. Indicators are selected according to certain criteria: (1) they have been adopted and accepted in other literature; (2) they should be simple and easy to spread; (3) they should well represent the meaning of the aspects; (4) the data are easy to obtain [51].

(1) Expenditure: this aspect refers to the financial devotion into and emphasis on sustainable higher education and reflects the coordinated interactions between sustainable higher education and the monetary supporters. 2 indicators are selected: revenue and expenditure of educational funds.

(2) Existence: this aspect refers to the competitiveness and performances of sustainable higher education itself. As this aspect measures higher education quantitatively, indicators should reflect the actual amount and status of sustainable higher education. 7 indicators are selected: number of higher education institutions, personnel, classrooms, magazines and books, and computers, areas occupied, and amount of fixed assets.

(3) Efficiency: this aspect refers to whether sustainable higher education interacts and performs efficiently. Indicators in this aspect should reflect the input and output ratio so that whether sustainable higher education performs efficiently can be evaluated. Besides, the efficiency of different stakeholders in sustainable higher education should be considered. Therefore, 5 indicators are selected: ratios of funds input-funds expense, education funds-student, student-100 thousand population, student-teacher, teachers with $\mathrm{PhD}$ degrees-all teachers, etc.

(4) Effectiveness: this aspect refers to the scientific research performances of sustainable higher education and reflects how sustainable higher education interacts with science and technology. The outcomes of the scientific research usually include academic papers, patents, publications, etc., and thus 4 indicators are selected in this aspect: number of scientific research projects, academic papers, patents, and publications.

(5) Economy: this aspect refers to the interaction between sustainable higher education and local economy; in detail, it reflects how sustainable higher education contributes to the economic growth. Take the case of China; the economic contribution of higher education is mainly from the national science parks operated by universities, and thus indicators relating to national university science parks are selected to evaluate the performance of the economy aspect. 4 indicators are selected: number of new tenants, income, and taxes paid and the space area.

(6) Equity: this aspect refers to the fairness of sustainable higher education. In other words, it reflects coordinated involvement of the public into sustainable higher education activities and the coordinated contribution of sustainable higher education to society. 2 indicators are selected: number of students in degree courses and students in nondegree courses.

(7) Equality: this aspect refers to the equality of women and international participations, which are the connotation of sustainability proposed by the UN, and reflects the interactions between sustainable higher education and equal society. As this aspect evaluates the quality of sustainable higher education, the indicators should be reflected as ratios. 4 indicators are selected: ratios of female staff, female research personnel, female students, and international students.

The 7E framework, consisting of 7 aspects and 28 indicators, is a new and improved one in evaluating sustainable higher education and enjoys several advantages. Firstly, the framework is integrated to evaluate sustainable higher education; second, the aspects and indicators well cover the connotations and goals of sustainability; third, the aspects are easy and clear enough, and the indicators are easy to obtain, making the widespread applications possible. The indicators of the 7E framework are shown in Table 1.

4.2. Data Descriptions. The data are selected from the following yearbooks of China (from 2013 to 2017): Educational Statistics Yearbook, Statistical Yearbook, Torch Statistical Yearbook, and Statistical Yearbook on Sciences and Technology, which guarantee the accuracy of data.

31 regions with the five-year data are selected in this study, and thus there are 155 alternatives in total (31 alternatives per year). In addition, there are 28 indicators in this study; therefore, there are 4,340 datasets in the data matrix. 


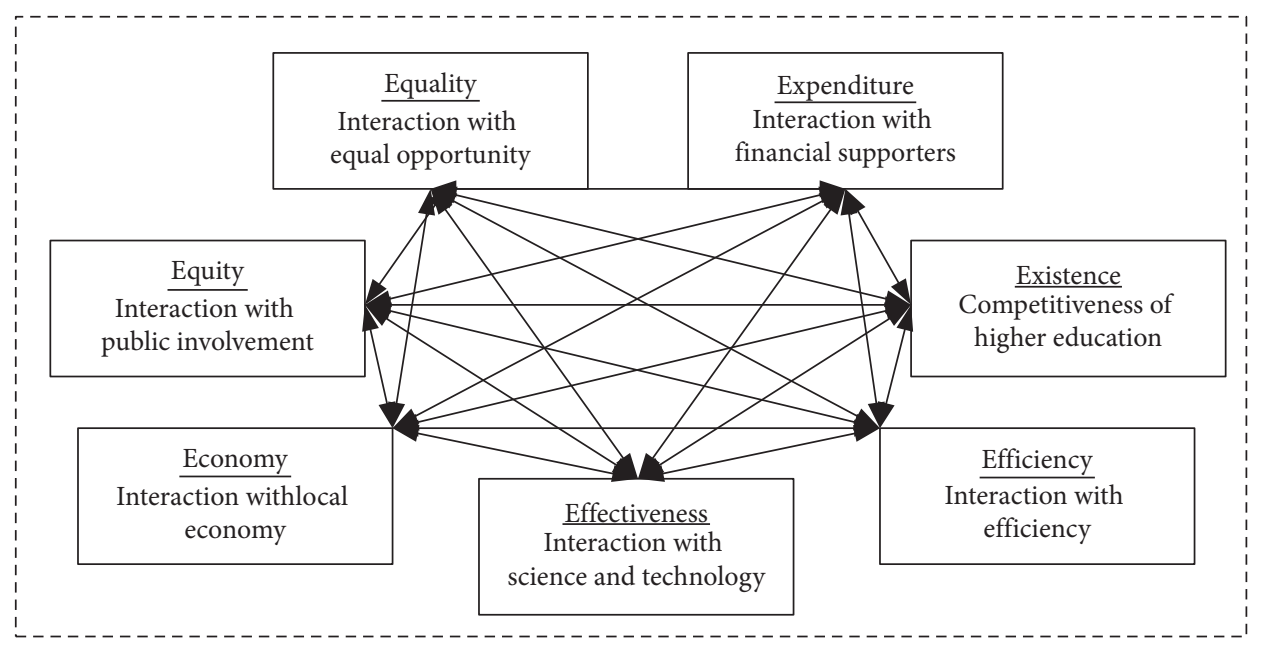

Figure 2: 7E framework.

TABLE 1: Indicators of the 7E framework.

\begin{tabular}{|c|c|}
\hline Aspect & Indicator \\
\hline Expenditure & $\begin{array}{l}\text { Revenue of educational funds } \\
\text { Expenditure of educational funds }\end{array}$ \\
\hline Existence & $\begin{array}{c}\text { No. of higher education institutions } \\
\text { No. of personnel } \\
\text { No. of classrooms } \\
\text { No. of magazines and books } \\
\text { No. of computers } \\
\text { Areas occupied } \\
\text { Amount of fixed assets }\end{array}$ \\
\hline Efficiency & $\begin{array}{c}\text { Ratio of funds input-funds expense } \\
\text { Ratio of education funds-student } \\
\text { Ratio of student-100 thousand population } \\
\text { Ratio of student-teacher } \\
\text { Ratio of teachers with PhD degrees-all teachers }\end{array}$ \\
\hline Effectiveness & $\begin{array}{l}\text { No. of scientific research projects } \\
\text { No. of academic papers } \\
\text { No. of patents } \\
\text { No. of publications }\end{array}$ \\
\hline Economy & $\begin{array}{l}\text { No. of new tenants in national science parks } \\
\text { Income from national science parks } \\
\text { Taxes paid by national science parks } \\
\text { Space area of national science parks }\end{array}$ \\
\hline Equity & $\begin{array}{l}\text { No. of students in degree courses } \\
\text { No. of students in nondegree courses }\end{array}$ \\
\hline Equality & $\begin{array}{c}\text { Ratio of female staff } \\
\text { Ratio of female research personnel } \\
\text { Ratio of female students } \\
\text { Ratio of international students }\end{array}$ \\
\hline
\end{tabular}

\subsection{Solution Steps}

4.3.1. Weight Calculation. IEW is used to calculate the weights of the indicators. The higher the value of IEW of the indicator, the larger the variances among the alternatives, the larger the weight of the indicator, and the more important the indicator within the sustainable higher education system. IEW calculates weights based on the statistical data, and thus it avoids subjectivity to some degree. The procedures are as follows.

(1) Data standardization: in this study, all the indicators are positive. $j$ is the indicator, and $i$ is the alternative; then, the matrix $x_{i j}$ can be obtained.

$$
x_{i j}^{\prime}=\frac{x_{i j}}{\sum_{i=1}^{n} x_{i j}} \text {. }
$$

$X=\left(x_{i j}^{\prime}\right)_{m \times n}(i=1,2, \ldots, m ; j=1,2, \ldots, n)$ is the standardized matrix. Here, we define $\max _{1 \leq j \leq n} x_{i j}$ and $\min _{1 \leq j \leq n} x_{i j}$ as the maximum and the minimum values of $j$.

(2) Calculate $f_{i j}$ :

$$
f_{i j}=\frac{1+x_{i j}^{\prime}}{\sum_{i=1}^{m}\left(1+X_{i j}^{\prime}\right)} .
$$

(3) Calculate information entropy $I$ :

$$
I_{j}=-\left(\sum_{i=1}^{m} f_{i j} \ln f i j\right) \text {. }
$$

(4) Calculate weight $W$ :

$$
W_{j}=\frac{1-I_{j}}{n-\sum_{j=1}^{n} I_{j}} .
$$

\subsubsection{Integrated Development Degree Calculation.} TOPSIS is effective to rank alternatives and has been widely utilized in various fields. By using TOPSIS, we can obtain the shortest distances of alternatives from the most preferred alternatives and the longest distances of alternatives from the least preferred alternatives. The procedures are as follows.

(1) Calculate the most preferred alternative $M$ and the least preferred alternative $L$ : 


$$
\begin{aligned}
M & =\left(\max _{1 \leq i \leq m} x_{i 1}, \max _{1 \leq i \leq m} x_{i 2}, \ldots, \max _{1 \leq i \leq m} x_{i n}\right), \\
L & =\left(\min _{1 \leq i \leq m} x_{i 1}, \min _{1 \leq i \leq m} x_{i 2}, \ldots, \min _{1 \leq i \leq m} x_{i n}\right) .
\end{aligned}
$$

(2) Calculate separation degree $S$ :

$$
\begin{aligned}
& S_{i}^{+}=\sqrt{\sum_{j=1}^{n} W_{j}\left(X_{i j}-M_{j}\right)^{2}}, \\
& S_{i}^{-}=\sqrt{\sum_{j=1}^{n} W_{j}\left(X_{i j}-L_{j}\right)^{2}} .
\end{aligned}
$$

(3) Calculate the integrated development degree of sustainable higher education (ID). ID reflects the relative closeness to the preferred alternative, and the higher value of ID represents the better development status of sustainable higher education in the region.

$$
\mathrm{ID}=\frac{S_{i}^{-}}{S_{i}^{+}+S_{i}^{-}} .
$$

The values of ID fluctuate between 0 and 1 , and the evaluation grades are constructed based on equal intervals. There are four grades, namely, poor (0.000-0.249), fair (0.250-0.499), good (0.500-0.749), and excellent (0.750-1.000), which objectively evaluate ID.

4.3.3. Coupling Coordination Degree Calculation. There are 7 aspects in evaluating sustainable higher education according to the 7E framework. These 7 aspects demonstrate the interactions of sustainable higher education with other factors and the interactions with each other (both accelerate and restrict each other). In addition, coupling means the interactions of the factors within the system, coordination means the harmonious status of the factors within the system [52], and coupling coordination means the interactive status and the overall evolutionary trends [53]. In this study, coupling coordination degree is useful and applicable to evaluate the interactive development status of the factors of sustainable higher education.

(1) Calculate coupling degree C. $K, V, U, Q, B, Z$, and $P$ are IDs of the 7 aspects of expenditure, existence, efficiency, effectiveness, economy, equity, and equality, respectively.

$$
C=\left\{\frac{K \times V \times U \times Q \times B \times Z \times P}{((K+V+U+Q+B+Z+P) / 7)^{7}}\right\}^{1 / 7} .
$$

(2) Calculate coordination degree T. $\sigma, \varepsilon, v, \omega, \chi, \theta$, and $\eta$ are the coefficients. These 7 aspects share the same importance to sustainable higher education and equally conduce to sustainable higher education; therefore, referring to former studies [54], the coefficients should be equal, and it is defined that $\sigma=0.143, \varepsilon=0.143, v=0.143, \omega=0.143, \chi=0.143$, $\theta=0.143$, and $\eta=0.142$.

$$
T=\sigma K+\varepsilon V+v U+\omega Q+\chi B+\theta Z+\eta P .
$$

(3) Calculate coupling coordination degree CD:

$$
\mathrm{CD}=\sqrt{C \times T}
$$

The evaluation grades of CD are constructed according to former studies [55]. There are 8 grades; higher value of CD means the better overall harmonious and coordinated status of the sustainable higher education system among the 7 aspects. The detailed classification is exhibited in Table 2.

\section{Results}

5.1. Discussion of ID. The IDs are exhibited in Table 3, and the temporal changes are exhibited in Figure 3. Overall, the IDs of most regions were fluctuating in the relatively low grades, whereas certain regions had relatively good performances with fluctuating changing trends. There are several detailed findings.

(1) Beijing and Jiangsu had the relatively higher integrated development statuses of sustainable higher education these years, though the development statuses were not stable and the fluctuations were large. Both regions fluctuated between the grade good (0.5-0.75) and grade excellent (0.75-0.1), demonstrating that these two places performed generally well in sustainable higher education. The leading roles of ID for these two regions were consistent with the current perception of the public regarding the sustainable higher education.

(2) Most regions performed less satisfactorily with mild fluctuations between the grade fair $(0.25-0.5)$ and poor (0-0.25). Among them, there were two interesting cases: Shanghai and Guizhou. Shanghai ranked at the third for ID in most years; however, it maintained fluctuations within the fair grade (0.25-0.5), which was not high enough. This was somehow unexpected as Shanghai was supposed to be one of the most attractive and competitive places for sustainable higher education from the public perspective; thus, the relatively fair ID performance of Shanghai hinted that more endeavors and efforts were demanded to further enhance ID. In addition, Guizhou was interesting mainly because of its sudden increase in 2015 (from poor to good). This was mainly because the performance of the economy aspect was in the top tier; in other words, the economical performances of the national university 
TABLE 2: Grade of CD.

\begin{tabular}{lcc}
\hline Range & Value of $\mathrm{CD}$ & Grade \\
\hline \multirow{2}{*}{ Incoordination } & $0.2>\mathrm{CD} \geq 0$ & Highly imbalanced \\
& $0.3>\mathrm{CD} \geq 0.2$ & $\begin{array}{c}\text { Moderately imbalanced } \\
\text { Slightly imbalanced }\end{array}$ \\
\hline \multirow{2}{*}{ Transitional coordination } & $0.4>\mathrm{CD} \geq 0.3$ & Approaching imbalance \\
& $0.5>\mathrm{CD} \geq 0.4$ & Reluctantly coordinated \\
\multirow{2}{*}{ Coordination } & $0.6>\mathrm{CD} \geq 0.5$ & Primarily coordinated \\
& $0.7>\mathrm{CD} \geq 0.6$ & Intermediately coordinated \\
& $0.8>\mathrm{CD} \geq 0.7$ & Highly coordinated \\
\hline
\end{tabular}

TABLE 3: Values of ID and CD.

\begin{tabular}{|c|c|c|c|c|c|c|c|c|c|c|}
\hline & \multicolumn{5}{|c|}{ ID } & \multicolumn{5}{|c|}{$\mathrm{CD}$} \\
\hline & 2013 & 2014 & 2015 & 2016 & 2017 & 2013 & 2014 & 2015 & 2016 & 2017 \\
\hline Jiangsu & 0.617 & 0.436 & 0.632 & 0.513 & 0.692 & 0.727 & 0.715 & 0.739 & 0.726 & 0.747 \\
\hline Beijing & 0.672 & 0.786 & 0.567 & 0.720 & 0.530 & 0.821 & 0.894 & 0.844 & 0.844 & 0.807 \\
\hline Shanghai & 0.481 & 0.383 & 0.433 & 0.374 & 0.432 & 0.714 & 0.722 & 0.722 & 0.702 & 0.713 \\
\hline Tibet & 0.061 & 0.050 & 0.063 & 0.046 & 0.061 & 0.000 & 0.000 & 0.000 & 0.000 & 0.000 \\
\hline Qinghai & 0.108 & 0.072 & 0.105 & 0.081 & 0.109 & 0.000 & 0.000 & 0.321 & 0.332 & 0.334 \\
\hline Xinjiang & 0.212 & 0.153 & 0.205 & 0.153 & 0.182 & 0.482 & 0.482 & 0.503 & 0.478 & 0.476 \\
\hline Ningxia & 0.106 & 0.063 & 0.107 & 0.105 & 0.115 & 0.000 & 0.000 & 0.382 & 0.378 & 0.380 \\
\hline Hainan & 0.120 & 0.091 & 0.230 & 0.152 & 0.165 & 0.000 & 0.000 & 0.444 & 0.422 & 0.435 \\
\hline Guangxi & 0.191 & 0.137 & 0.190 & 0.168 & 0.197 & 0.000 & 0.000 & 0.516 & 0.501 & 0.506 \\
\hline Tianjin & 0.264 & 0.214 & 0.217 & 0.206 & 0.238 & 0.567 & 0.573 & 0.551 & 0.559 & 0.556 \\
\hline Shanxi & 0.178 & 0.128 & 0.146 & 0.128 & 0.151 & 0.413 & 0.405 & 0.408 & 0.429 & 0.429 \\
\hline Inner Mongolia & 0.141 & 0.105 & 0.147 & 0.138 & 0.168 & 0.000 & 0.000 & 0.465 & 0.462 & 0.473 \\
\hline Hunan & 0.264 & 0.194 & 0.235 & 0.239 & 0.273 & 0.556 & 0.540 & 0.549 & 0.562 & 0.556 \\
\hline Hubei & 0.389 & 0.296 & 0.353 & 0.301 & 0.354 & 0.627 & 0.622 & 0.636 & 0.624 & 0.629 \\
\hline Sichuan & 0.362 & 0.258 & 0.284 & 0.290 & 0.312 & 0.594 & 0.591 & 0.598 & 0.597 & 0.595 \\
\hline Shaanxi & 0.288 & 0.220 & 0.251 & 0.209 & 0.258 & 0.580 & 0.574 & 0.584 & 0.559 & 0.578 \\
\hline Heilongjiang & 0.298 & 0.224 & 0.246 & 0.267 & 0.294 & 0.566 & 0.566 & 0.564 & 0.569 & 0.569 \\
\hline Zhejiang & 0.345 & 0.246 & 0.303 & 0.278 & 0.323 & 0.643 & 0.631 & 0.654 & 0.637 & 0.646 \\
\hline Guangdong & 0.326 & 0.294 & 0.345 & 0.282 & 0.344 & 0.639 & 0.662 & 0.646 & 0.654 & 0.673 \\
\hline Jiangxi & 0.260 & 0.193 & 0.237 & 0.214 & 0.250 & 0.522 & 0.504 & 0.512 & 0.514 & 0.515 \\
\hline Chongqing & 0.248 & 0.199 & 0.223 & 0.200 & 0.218 & 0.546 & 0.551 & 0.549 & 0.539 & 0.533 \\
\hline Shandong & 0.373 & 0.289 & 0.397 & 0.321 & 0.322 & 0.627 & 0.625 & 0.654 & 0.633 & 0.619 \\
\hline Anhui & 0.244 & 0.182 & 0.225 & 0.206 & 0.238 & 0.517 & 0.512 & 0.529 & 0.527 & 0.530 \\
\hline Yunnan & 0.256 & 0.198 & 0.252 & 0.209 & 0.245 & 0.536 & 0.530 & 0.548 & 0.530 & 0.535 \\
\hline Henan & 0.305 & 0.231 & 0.280 & 0.272 & 0.316 & 0.560 & 0.542 & 0.563 & 0.567 & 0.568 \\
\hline Guizhou & 0.140 & 0.106 & 0.554 & 0.140 & 0.183 & 0.000 & 0.000 & 0.533 & 0.467 & 0.491 \\
\hline Gansu & 0.213 & 0.154 & 0.188 & 0.168 & 0.195 & 0.493 & 0.489 & 0.499 & 0.490 & 0.487 \\
\hline Fujian & 0.225 & 0.160 & 0.184 & 0.180 & 0.212 & 0.000 & 0.519 & 0.520 & 0.530 & 0.537 \\
\hline Jilin & 0.224 & 0.161 & 0.187 & 0.206 & 0.203 & 0.533 & 0.517 & 0.521 & 0.535 & 0.517 \\
\hline Hebei & 0.296 & 0.215 & 0.276 & 0.231 & 0.269 & 0.531 & 0.517 & 0.534 & 0.518 & 0.525 \\
\hline Liaoning & 0.321 & 0.241 & 0.313 & 0.252 & 0.307 & 0.599 & 0.587 & 0.612 & 0.595 & 0.601 \\
\hline
\end{tabular}

science parks contributed to the high ID of that year. Furthermore, the rest of the regions exhibited mild fluctuations, which were not good signs as it could be interpreted that most regions performed similarly without obvious growth. Therefore, effective actions were required to enhance ID for each region, respectively.

From the spatial perspective, the average IDs showed certain spatial correlations (Figure 4). There were several findings.
(1) The coastal regions had higher IDs compared with the noncoastal regions. For the 11 coastal regions (Hainan, Guangdong, Hebei, Zhejiang, Shandong, Fujian, Jiangsu, Shanghai, Tianjin, Liaoning, and Guangxi), 6 regions had the average IDs no lower than the grade fair (0.25-0.5); on the contrary, for the remaining 20 noncoastal regions, only 5 regions, including Beijing, Heilongjiang, Sichuan, Hubei, and Henan, were in the grade fair $(0.25-0.5)$ or good $(0.5-0.75)$, and 15 regions were in the grade poor 


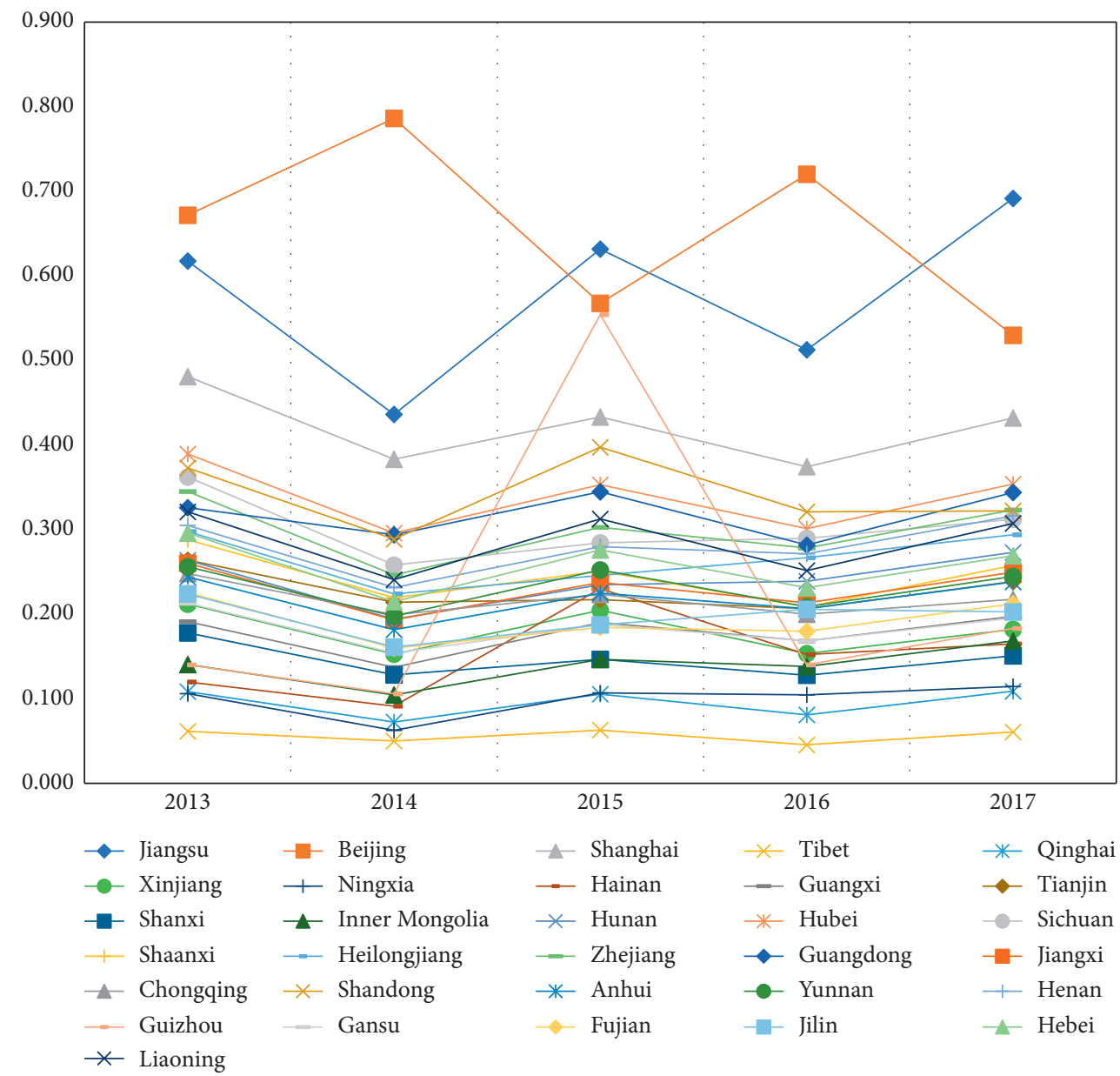

Figure 3: Temporal changes of ID.

(0-0.25) for the average IDs. Such differences demonstrated the spatial imbalance between the coastal regions and other regions.

(2) The central part of China (Henan and Hubei) performed relatively more outstanding compared with other parts. Located in the central part, Henan and Hubei were in the grade fair $(0.25-0.5)$, which was mainly because they had long and prestigious history in higher education of China, and both shared population advantages both qualitatively and quantitatively in sustainable higher education development. Therefore, they enjoyed relatively fair grade in ID.

5.2. Discussion of CD. The CDs are exhibited in Table 3, and the temporal changes are exhibited in Figure 5. Overall, the trends of CDs were mildly fluctuating for most regions, whereas certain regions changed rapidly. There were several findings.

(1) Beijing, Jiangsu, and Shanghai were at the top 3 with mild fluctuations, but the trends of the coupling coordination of sustainable higher education were apparently different. For Beijing, the continuously first of CD, was the only region where the CDs remained highly coordinated (above 0.8 ); however, it witnessed the gradual decline of CD and was likely to be surpassed by other regions. Jiangsu and Shanghai were mildly fluctuating within the intermediate coordination grade (0.7-0.8) for these years, but Jiangsu was gradually increasing and the gap between Jiangsu and Beijing was declining. It is obvious that Jiangsu was developing sustainable higher education with comprehensiveness and integration these years so that the CD was improving. Shanghai showed the stableness without obvious enhancement trends, and the gap with Jiangsu would be enlarged. For the top regions such as Beijing and Shanghai, further effective countermeasures should be taken to prevent further decline and to enhance coordinated development of sustainable higher education.

(2) Tibet maintained stability in terms of CD with the highly imbalanced status. Tibet was the only region whose CDs were 0 for the continuous five years, which proved the continuous imbalanced development of sustainable higher education. In detail, Tibet did not have any contributions in the aspect of economy, mainly due to the fact that there were not 


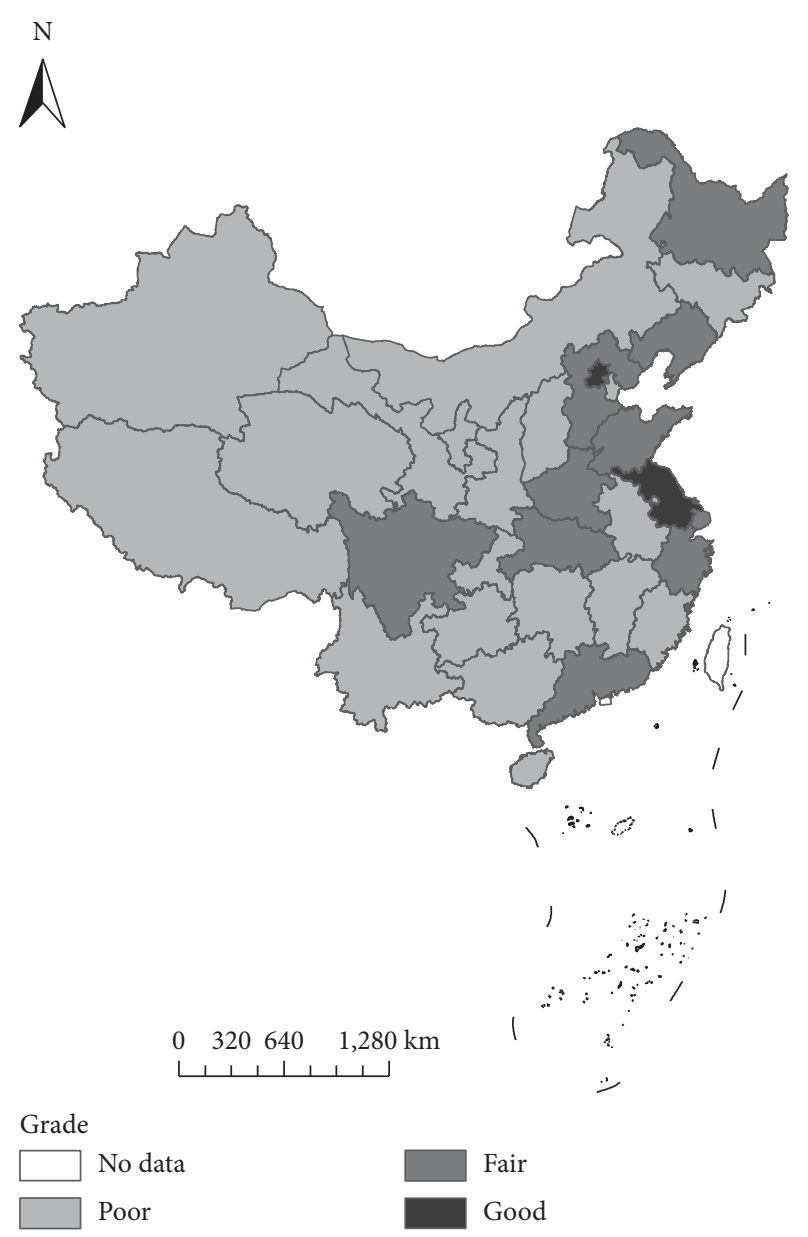

FIgURE 4: Spatial correlation of ID.

any national university science parks. Therefore, it is urgent for Tibet to set up university science parks so that the sustainable higher education can interact with local economy with coordination.

(3) Several regions witnessed huge increase from the high imbalance grade (0.000) to higher coordination grades. For instance, Fujian from high imbalance in 2013 moved to reluctant coordination (0.519) in 2014 and then kept the status quo for the next years; in 2015, Guizhou and Guangxi increased to the reluctant coordination grade (0.5-0.6), Hainan and Inner Mongolia increased to the approaching imbalance grade (0.4-0.5), and Ningxia and Qinghai increased to the slight imbalance grade (0.3-0.4). The huge increases of these regions shared similarities: they were highly imbalanced due to the lack of national university science parks and the uncoordinated development of sustainable higher education in the economy aspect; in the later years, the science parks were constructed in these regions and the economy aspect of sustainable higher education started to have effects so that the CDs rapidly increased and the sustainable higher education changed to relatively more coordinated statuses.
From the spatial perspective, the variations of CDs are exhibited in Figure 6 . There were several findings regarding the spatial distributions of CD.

(1) The CDs of the northwestern regions were apparently lower than other regions. If a line was drawn connecting Heilongjiang and Sichuan, it can be found that the left side of this line (namely, the northwestern regions) was apparently lower in CD, while the right side of the line (namely, the remaining regions) had higher CDs. This demonstrated that the northwestern regions had relatively uncoordinated development statuses of sustainable higher education compared with other places. In detail, these regions were mainly weak in the aspects of economy, equity, and equality: the sustainable higher education of these places had weak interactions with or contributions to the local economy, education fairness, and equality.

(2) The coastal regions had higher CDs than other regions, which was consistent with the IDs. The coastal regions were mainly in or above the primary coordination grade $(0.6-0.7)$, proving these regions had better coupling coordination statuses of sustainable higher education. These regions develop sustainable higher education comprehensively and coordinatively, which should be maintained and should be spread to other less-coordinated regions.

(3) Though there were differences of CDs among regions, the gaps were declining. It was noticeable in 2013 that most northwestern and southwestern regions were in the high imbalance grade, proving the less coordinated statuses in sustainable higher education compared with other places; as time passed by, these regions gradually improved and decreased the gaps with other regions. For instance, Guangxi grew to the reluctant coordination grade $(0.5-0.6)$ in 2017, which was the same as the surrounding regions. The decline of the $\mathrm{CD}$ gaps demonstrated that the national preferential policies aiming to enhance sustainable higher education in less developed areas had made significant impact.

\section{Countermeasures}

There are differences of IDs and CDs among regions of China; therefore, it is needed for different regions to take effective and efficient approaches to develop sustainable higher education, respectively. In specific, the following countermeasures could be considered.

For the northwestern regions where the IDs and CDs are low, it is needed to develop sustainable higher education with endeavors, promote interactions between sustainable higher education and other related factors, and realize coordination among higher education aspects.

(1) Make up the shortages: reconsider the connotation of sustainability, decrease the effects of the innate disadvantages, and take advantage of the opportunities. For Tibet, university science parks are strongly 


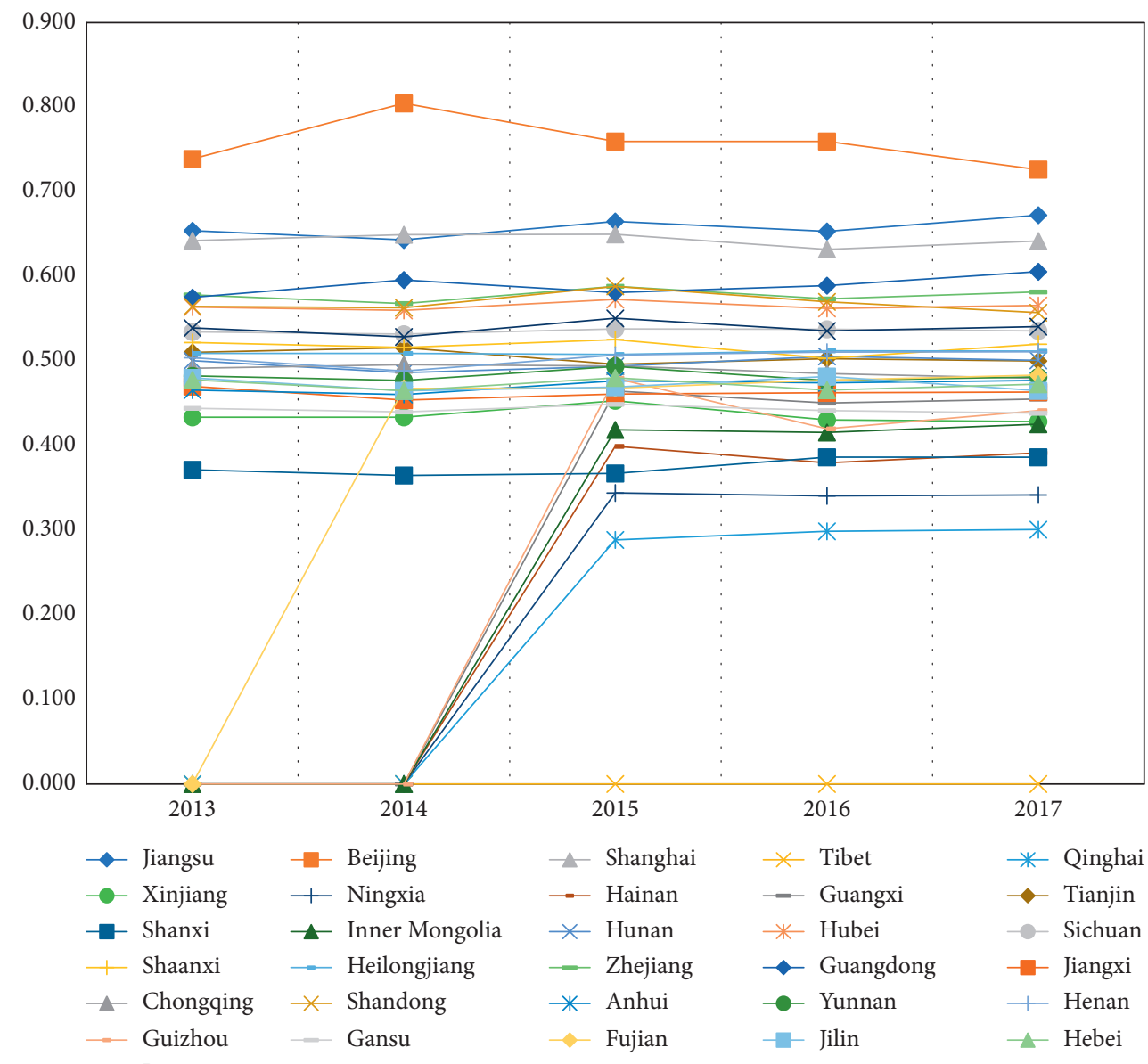

Figure 5: Temporal changes of CD.

encouraged to be constructed and developed in order to enhance the comprehensive development in the economy aspect. The same happens to other northwestern regions such as Ningxia and Qinghai as they are also less competitive in this aspect.

(2) Continuously use national preferential policies for apparent development: it has been found that the gaps of sustainable higher education between the northwestern regions and other places have declined after the initiation of certain national strategies, so the sustainable development pattern in higher education should be continued by using national strategies such as the Outline of Education Reform and Development and the Belt and Road Initiatives and by using the geographical strengths to enhance international cooperation with surrounding countries. In detail, it is suggested for Ningxia and Hainan to enhance the effectiveness aspect by utilizing the preferential policies of national social sciences or national sciences foundations. In addition, the border regions such as Inner Mongolia can accelerate the development of multinational cooperation under the national frames in order to promote the performance of the equality aspect.
For the coastal regions where IDs and CDs are in better grades, it is needed to look for new methodologies and explore new highlights of sustainable higher education. There are several countermeasures.

(1) Explore new strategies or policies of sustainable higher education: improve relevant policies, introduce new policies, and set up demonstration areas so that the innovative and new policies could be the new leading factors to enhance sustainable higher education. For example, Tianjin can innovatively improve former policies of sustainable higher education in the background of constructing Tianjin Pilot Free Trade Zone and introduce new policies in order to encourage sustainable higher education to interactively support the Trade Zone development so that these improved policies can be the new impetus to accelerate sustainable higher education growth.

(2) Explore new development modes of sustainable higher education: try to discover new development modes of sustainable higher education to make it more competitive and make the coupling coordination among the aspects of sustainable higher education more benign. As the top regions, Jiangsu 


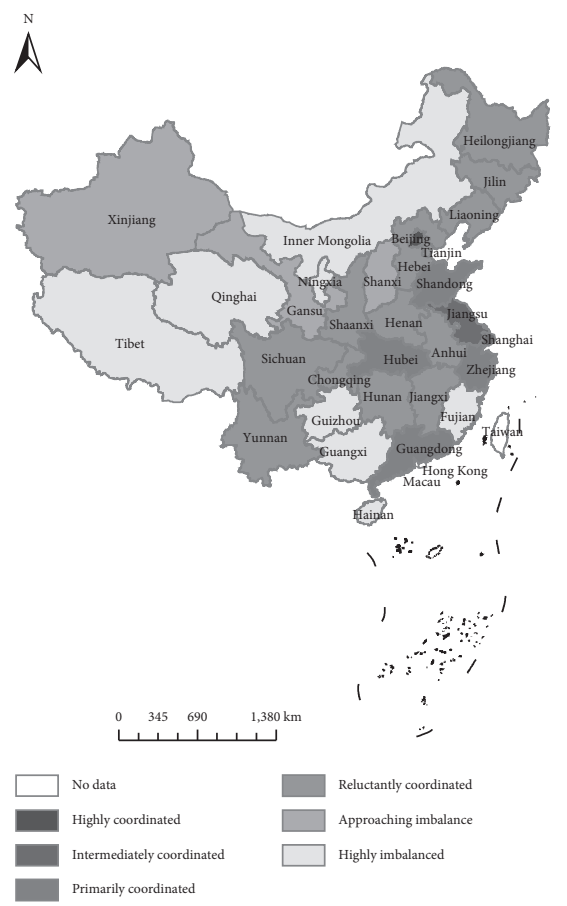

(a)
A

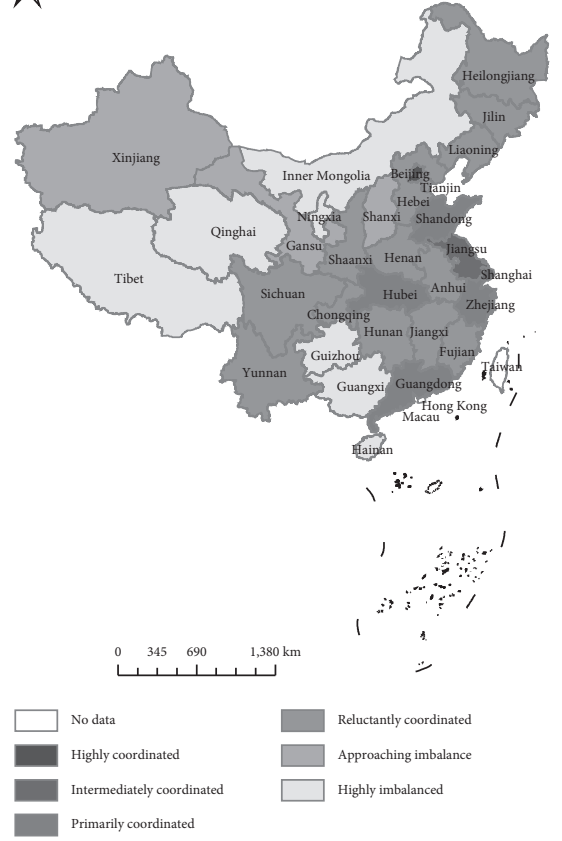

(b)
$\AA$

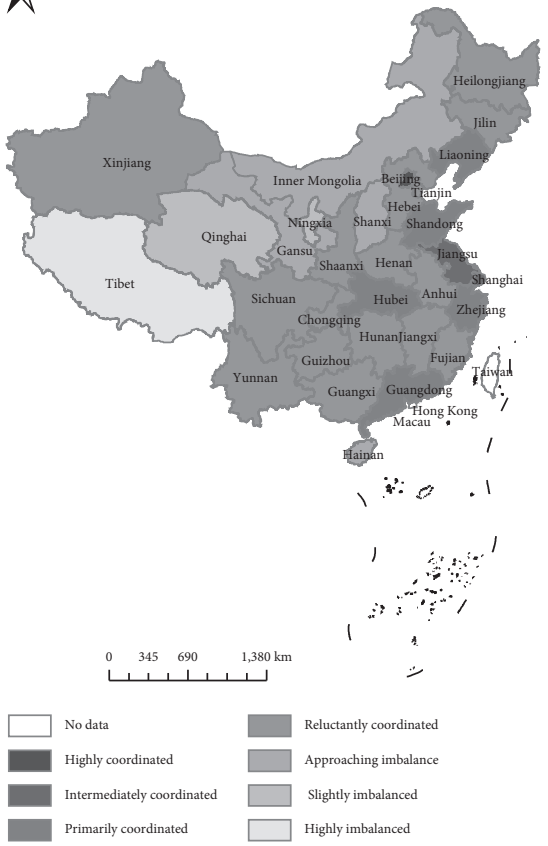

(c)
$\AA^{N}$

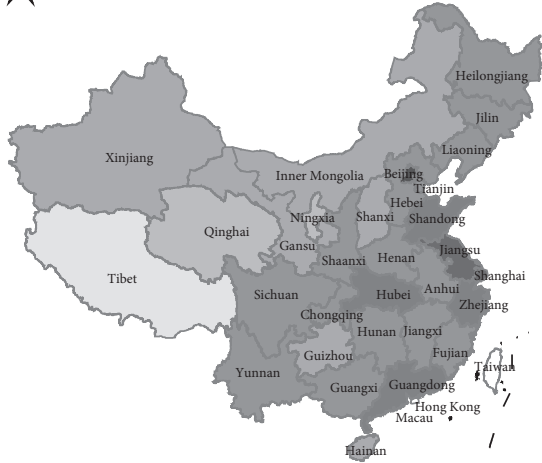

$1: 0.1$

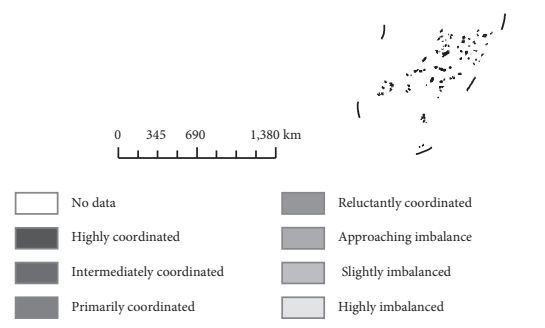

(d)
A

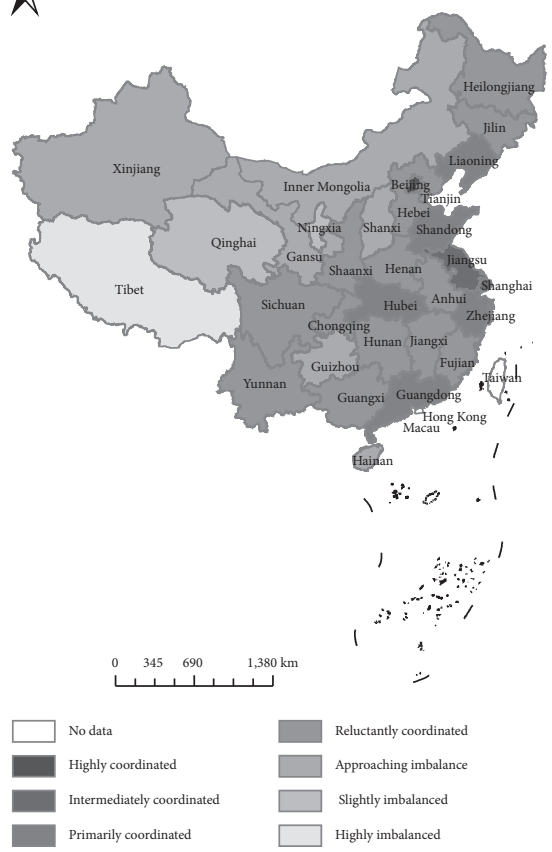

(e)

FIgure 6: The spatial variation of CD: (a-e) 2013-2017.

and Shanghai should endeavor to learn from countries which enjoy advanced sustainable higher education and explore new and suitable modes of sustainable higher education so that the leading roles can be maintained. Especially, Shanghai needs to devote increasing resources and efforts in sustainable higher education in order to suppress the stableness of CDs.
For the rest of the regions where the IDs and CDs have average performances, specific and proper countermeasures aiming to enhance ID and CD are suggested. There are several countermeasures.

(1) Share resources through cooperation: enhance multilateral cooperation and communication and learn from other regions' experiences. More 
cooperation channels should be created, for example, the communication and integration between sustainable higher education resources and business resources are suggested. In specific, Shanxi should encourage the involvement of public resources to sustainable higher education in order to enhance the coordination of coupling in the effectiveness aspect.

(2) Develop with specific features: reconsider and conclude one's special characteristics, strengths, weakness, opportunities, and threats, segment the development path, make correct and matched positioning, and enhance ID and CD with precise approaches. In detail, Sichuan needs to rethink the equality aspect of sustainable higher education, explore the innate advantages, illustrate its special competitiveness in attracting female and international citizens, make precise campaigns to females and international students, and increase the ratio of females and international students in higher education so that the sustainable higher education will be more coordinated.

\section{Conclusions}

This article constructs a new framework (7E framework) to evaluate sustainable higher education and studies the integrated development and coordination statuses of the 31 regions of China with the statistics from 2013 to 2017 and draws some conclusions.

(1) The integrated development degrees of sustainable higher education in most regions are fluctuating in the relatively low grades, whereas certain regions have relatively good performances with fluctuating changing trends; Beijing and Jiangsu have the relatively higher integrated development statuses of sustainable higher education these years, though the development statuses are not stable and the fluctuations are large. From the spatial perspective, the coastal regions perform better than the noncoastal regions, and the central part of China performs relatively outstanding.

(2) The coupling coordination degrees of sustainable higher education in most regions are mildly fluctuating, whereas certain regions change rapidly. There are some typical regions: Beijing, Jiangsu, and Shanghai are at the top 3 with mild fluctuations, but the trends are apparently different; Tibet maintains stability with the highly imbalanced status. Spatially, the coupling coordination degrees of the northwestern regions are apparently lower and those of the coastal regions are higher, but the gaps among regions are declining.

(3) There are temporal and spatial differences of the sustainable higher education statuses among regions; therefore, different regions should take corresponding effective and efficient approaches to develop sustainable higher education, respectively.
Northwestern regions should develop sustainable higher education with endeavors and promote interactions between sustainable higher education and other related factors; coastal regions should look for new methodologies and new highlights of sustainable higher education; the remaining regions should promote specific, matched, and proper countermeasures aiming to promote sustainable higher education.

There are some highlights.

(1) The 7E framework is a new and improved one to evaluate sustainable higher education. It has several advantages. Firstly, the framework is more comprehensive to evaluate sustainable higher education; second, the aspects and indicators well cover the connotations and goals of sustainability; third, the aspects are easy and clear enough, and the indicators are easy to obtain, making the widespread global communications and applications possible.

(2) The combination of IEW and TOPSIS is useful to objectively evaluate the development and coordination statuses of sustainable higher education. This method is advanced than other approaches in sustainable higher education evaluation, such as the analytic hierarchy process analysis and Delphi method, which are subjective and may be biased because of personal preferences.

(3) The applicable countermeasures according to the specific characteristics of the regions are useful to improve the coordinated development of sustainable higher education and contribute to application of the $7 \mathrm{E}$ framework theories in the future with a new and innovative perspective.

\section{Data Availability}

The data used to support the findings of the study are available from the corresponding author upon request.

\section{Conflicts of Interest}

The authors declare that they have no conflicts of interest.

\section{Authors' Contributions}

Y.G. was responsible for conceptualization, methodology, validation, original draft preparation, supervision, and project administration. H.Z. and Q.Z. reviewed and edited the manuscript. N.Z. was responsible for software, investigation, resources, and data curation. H.Z. visualized the study. N.Z. and Q.Z. contributed to formal analysis. H.Z. and Y.G. were responsible for funding acquisition.

\section{Acknowledgments}

This research was funded by the Ministry of Education Project of Humanities and Social Science (grant no. 14YJC751059), Shanghai Municipal Education Commission 
(grant no. ZZSDJU19012), Shanghai CCP Committee of Education and Health Work (grant no. TZYJ-2019-B37), and Shanghai Dianji University (grant nos. B1-0288-20-00701-22 and 19AR20).

\section{References}

[1] P. M. Romer, "Endogenous technological change," Journal of Political Economy, vol. 98, no. 5, pp. S71-S102, 1990.

[2] Education-United Nations Sustainable Development, 2019, https://www.un.org/sustainabledevelopment/education/.

[3] Grasp the Strategic Opportunities of Higher Education Development, 2018, http://www.jyb.cn/zgjyb/201803/ t20180310_1016842.html.

[4] G. Zhou and S. Luo, "Higher education input, technological innovation, and economic growth in China," Sustainability, vol. 10, no. 8, p. 2615, 2018.

[5] B. A. Boyce, J. L. Lund, G. Napper-Owen, and D. Almarode, "Doctoral students' perspectives on their training as researchers in higher education," Quest, vol. 71, no. 3, pp. 277-288, 2019.

[6] W. L. Filho, V. R. Vargas, A. L. Salvia et al., "The role of higher education institutions in sustainability initiatives at the local level," Journal of Cleaner Production, vol. 233, pp. 1004-1015, 2019.

[7] D. He, M. Zheng, W. Cheng, Y.-y. Lau, and Q. Yin, "Interaction between higher education outputs and industrial structure evolution: evidence from Hubei province, China," Sustainability, vol. 11, no. 10, p. 2923, 2019.

[8] H. Etzkowitz and L. Leydesdorff, "The dynamics of innovation: from national systems and "mode 2" to a triple helix of university-industry-government relations," Research Policy, vol. 29, no. 2, pp. 109-123, 2000.

[9] R. Shawe, W. Horan, R. Moles, and B. O’Regan, “Mapping of sustainability policies and initiatives in higher education institutes," Environmental Science \& Policy, vol. 99, pp. 80-88, 2019.

[10] Y. Ge and K. C. Ho, "The cultivation of research labor in Pacific Asia with special reference to Singapore," Asia Pacific Education Review, vol. 19, no. 2, pp. 199-210, 2018.

[11] R. Shields, "The sustainability of international higher education: student mobility and global climate change," Journal of Cleaner Production, vol. 217, pp. 594-602, 2019.

[12] L. Guo, J. Huang, and Y. Zhang, "Education development in China: education return, quality, and equity," Sustainability, vol. 11, no. 13, p. 3750, 2019.

[13] C. Farinha, S. Caeiro, and U. Azeiteiro, "Sustainability strategies in Portuguese higher education institutions: commitments and practices from internal insights," Sustainability, vol. 11, no. 11, p. 3227, 2019.

[14] A. Alghamdi, H. Haider, K. Hewage, and R. Sadiq, "Interuniversity sustainability benchmarking for Canadian higher education institutions: water, energy, and carbon flows for technical-level decision-making," Sustainability, vol. 11, no. 9, p. 2599, 2019.

[15] P. J. Ramísio, L. M. C. Pinto, N. Gouveia, H. Costa, and D. Arezes, "Sustainability strategy in higher education institutions: lessons learned from a nine-year case study," Journal of Cleaner Production, vol. 222, pp. 300-309, 2019.

[16] D. Alba-Hidalgo, J. Benayas del Álamo, and J. GutiérrezPérez, "Towards a definition of environmental sustainability evaluation in higher education," Higher Education Policy, vol. 31, no. 4, pp. 447-470, 2018.
[17] J. L. Pressler and C. A. Kenner, "Return on investment," Nurse Educator, vol. 39, pp. 1-51, 2014.

[18] M. Juárez-Nájera, H. Dieleman, and S. Turpin-Marion, "Sustainability in Mexican Higher Education: towards a new academic and professional culture," Journal of Cleaner Production, vol. 14, no. 9-11, pp. 1028-1038, 2006.

[19] L. Morley, "Gender equity in Commonwealth higher education," Women's Studies International Forum, vol. 28, no. 23, pp. 209-221, 2005.

[20] P. Madzík, P. Budaj, and A. Chocholáková, "Practical experiences with the application of corporate social responsibility principles in a higher education environment," Sustainability, vol. 10, no. 6, p. 1736, 2018.

[21] United Nations Environment Programme, Making Tourism More Sustainable: A Guide for Policy Makers, World Tourism Organization Publications, Madrid, Spain, 2005.

[22] G. Serrano, F. Llamazares, and F. Otamendi, "Measurement and sustainability of the qualifications frameworks in the European higher education area through an employment survey on access to the labour market," Sustainability, vol. 7, no. 10, pp. 13777-13812, 2015.

[23] F. D. Guillen-Gamez and M. J. Mayorga-Fernandez, "Identification of variables that predict teachers' attitudes toward ICT in higher education for teaching and research: a study with regression," Sustainability, vol. 12, no. 4, p. 1312, 2020.

[24] A. Nursall, "Building public knowledge: collaborations between science centres, universities and industry," International Journal of Technology Management, vol. 25, no. 5, pp. 381-389, 2003.

[25] D. Zavrl, "Cooperation and competition among centers for economic development (CEDS)," Ekonomska Istraživanja, vol. 21, no. 4, pp. 106-114, 2008.

[26] N. Bennett, E. Dunne, and C. Carré, Skills Development in Higher Education and Employment, Taylor \& Francis, Inc., Florence, KY, USA, 2000.

[27] J. Brunstein and J. King, "Organizing reflection to address collective dilemmas: engaging students and professors with sustainable development in higher education," Journal of Cleaner Production, vol. 203, pp. 153-163, 2018.

[28] L. Sanchez, J. Alfonso-Cendon, H. Perez, H. Quintian, and E. Corchado, "Skills development of professional ethics in engineering degrees in the European higher education area," in Proceedings of the International Joint Conference SOCO16CISIS16-ICEUTE16, vol. 527, pp. 736-740, San Sebastin, Spain, 2017.

[29] P. Thanomwan, K. N. Tang, T. Prakittiya, and P. Sermpong, "The effect of risk management and student characteristics on life skills of higher education students," Pertanika Journal of Social Sciences and Humanities, vol. 25, pp. 891-906, 2017.

[30] J. Kabók, S. Radišić, and B. Kuzmanović, "Cluster analysis of higher-education competitiveness in selected European countries," Economic Research-Ekonomska Istraživanja, vol. 30, no. 1, pp. 845-857, 2017.

[31] I. Liefner, "Funding, resource allocation, and performance in higher education systems," Higher Education, vol. 46, no. 4, pp. 469-489, 2003.

[32] P. Boyadjieva and P. Ilieva-Trichkova, "From conceptualisation to measurement of higher education as a common good: challenges and possibilities," Higher Education, vol. 77, no. 6, pp. 1047-1063, 2019.

[33] A. A. Selyutin, T. V. Kalashnikova, N. E. Danilova, and N. V. Frolova, "Massification of the higher education as a way to individual subjective wellbeing," in Proceedings of the III 
International Scientific Symposium on Lifelong Wellbeing in the World, vol. 19, pp. 258-263, Tomsk Polytechnic University, Tomsk, Russia, 2017.

[34] A. E. Raftery and M. Hout, "Maximally maintained inequality: expansion, Reform, and opportunity in Irish education, 1921-1975," Sociology of Education, vol. 66, no. 1, pp. 41-62, 1993.

[35] S. R. Lucas, "Effectively maintained inequality: education transitions, track mobility, and social background effects," American Journal of Sociology, vol. 106, no. 6, pp. 1642-1690, 2001.

[36] E. Del Rey and M. Racionero, "Financing schemes for higher education," European Journal of Political Economy, vol. 26, no. 1, pp. 104-113, 2010.

[37] J. Seale, "How can we confidently judge the extent to which student voice in higher education has been genuinely amplified? A proposal for a new evaluation framework," Research Papers in Education, vol. 31, no. 2, pp. 212-233, 2016.

[38] C. Leathwood and D. Phillips, "Developing curriculum evaluation research in higher education: process, politics and practicalities," Higher Education, vol. 40, no. 3, pp. 313-330, 2000.

[39] X. Wen, Y. N. Yin, and J. Xu, "Evaluation and analysis of competitiveness of regional higher education in China based on individual advantage characteristic," Educational Sciences: Theory \& Practice, vol. 18, pp. 1459-1472, 2018.

[40] J. Brunstein, P. Jaime, D. P. Curi, M. J. d`Angelo, and E. W. Mainardes, "Assessment and evaluation of higher education in business management: an analysis of the Brazilian case in the light of social learning theory for sustainability," Assessment \& Evaluation in Higher Education, vol. 40, no. 6, pp. 833-854, 2015.

[41] J. Li, H. Fang, S. Fang, and S. Siddika, "Investigation of the relationship among university-research institute-industry innovations using a coupling coordination degree model," Sustainability, vol. 10, no. 6, p. 1954, 2018.

[42] Z. Weidong, "Research on resource utilization efficiency of universities in Heilongjiang province based on principal component analysis," Heilongjiang Research on Higher Education, vol. 193, no. 5, pp. 43-45, 2010, in Chinese.

[43] L. Ding and Y. Zeng, "Evaluation of Chinese higher education by TOPSIS and IEW - the case of 68 universities belonging to the Ministry of Education in China," China Economic Review, vol. 36, pp. 341-358, 2015.

[44] J.-K. Chen and I.-S. Chen, "Using a novel conjunctive MCDM approach based on DEMATEL, fuzzy ANP, and TOPSIS as an innovation support system for Taiwanese higher education," Expert Systems with Applications, vol. 37, no. 3, pp. 1981-1990, 2010.

[45] S. Guoqi, "Study on dynamic-classified management of private high education based on grey-relation TOPSIS valuation model," Modern Education Management, vol. 12, pp. 89-94, 2014, in Chinese.

[46] A. García-Aracil and D. Palomares-Montero, "Indicadores para la evaluación de las instituciones universitarias: validación a través del método Delphi," Revista Española de Documentación Científica, vol. 35, no. 1, pp. 119-144, 2012.

[47] A. Moeini, M. S. Pishvaee, and M. Dezfuli, "Study of cultural and social indicators of universities and higher education institutions of the Islamic Republic of Iran based on the upstream documents of the country by the combination of BSC and KPI method and their ranking using AHP technique," Acta Medica Mediterranea, vol. 34, pp. 575-581, 2018.
[48] C. E. Shannon, "A mathematical theory of communication," Bell System Technical Journal, vol. 27, no. 3, pp. 379-423, 1948.

[49] Z. Tang, "An integrated approach to evaluating the coupling coordination between tourism and the environment," Tourism Management, vol. 46, pp. 11-19, 2015.

[50] C. Liu, R. Zhang, M. Wang, and J. Xu, "Measurement and prediction of regional tourism sustainability: an analysis of the yangtze river economic Zone, China," Sustainability, vol. 10, no. 5, p. 1321, 2018.

[51] Y. Geng, M. Maimaituerxun, and H. Zhang, "Coupling coordination of water governance and tourism: measurement and prediction," Discrete Dynamics in Nature and Society, vol. 2020, Article ID 3683918, 13 pages, 2020.

[52] Y. Geng, Z. Wei, H. Zhang, and M. Maimaituerxun, “Analysis and prediction of the coupling coordination relationship between tourism and air environment: yangtze river economic Zone in China as example," Discrete Dynamics in Nature and Society, vol. 2020, Article ID 1406978, 15 pages, 2020.

[53] Q. Zheng, Y. Kuang, and N. Huang, "Coordinated development between urban tourism economy and transport in the pearl river delta, China," Sustainability, vol. 8, no. 12, p. 1338, 2016.

[54] Y. Tan and Y. Geng, "Coupling coordination measurement of environmental governance: case of China," Environmental and Ecological Statistics, vol. 27, 2020.

[55] Y. Geng and Y. Tan, "Measurement and prediction: coupling coordination of finance and air environment," Discrete Dynamics in Nature and Society, vol. 2020, Article ID 8673965, 12 pages, 2020. 